\title{
How Accurate is Your Sclerostin Measurement? Comparison Between Three Commercially Available Sclerostin ELISA Kits
}

\author{
Isabelle Piec $^{1} \cdot$ Christopher Washbourne $^{1} \cdot$ Jonathan Tang $^{1} \cdot$ Emily Fisher $^{1} \cdot$ \\ Julie Greeves $^{2} \cdot$ Sarah Jackson $^{2} \cdot$ William D. Fraser ${ }^{1,3}$
}

Received: 27 July 2015/Accepted: 30 November 2015/Published online: 9 January 2016

(c) The Author(s) 2016. This article is published with open access at Springerlink.com

\begin{abstract}
Sclerostin, bone formation antagonist is in the spotlight as a potential biomarker for diseases presenting with associated bone disorders such as chronic kidney disease (CDK-MBD). Accurate measurement of sclerostin is therefore important. Several immunoassays are available to measure sclerostin in serum and plasma. We compared the performance of three commercial ELISA kits. We measured sclerostin concentrations in serum and EDTA plasma obtained from healthy young (18-26 years) human subjects using kits from Biomedica, TECOmedical and from R\&D Systems. The circulating sclerostin concentrations were systematically higher when measured with the Biomedica assay (serum: $35.5 \pm 1.1 \mathrm{pmol} / \mathrm{L}$; EDTA: $39.4 \pm 2.0$ $\mathrm{pmol} / \mathrm{L}$; mean $\pm \mathrm{SD}$ ) as compared with TECOmedical (serum: $21.8 \pm 0.7 \mathrm{pmol} / \mathrm{L}$; EDTA: $27.2 \pm 1.3 \mathrm{pmol} / \mathrm{L}$ ) and R\&D Systems (serum: $7.6 \pm 0.3 \mathrm{pmol} / \mathrm{L}$; EDTA: $30.9 \pm 1.5 \mathrm{pmol} / \mathrm{L}$ ). We found a good correlation between the assay for EDTA plasma $(r>0.6 ; p<0.001)$ while in serum, only measurements obtained using TECOmedical and R\&D Systems assays correlated significantly $(r=0.78$; $p<0.001)$. There was no correlation between matrices results when using the Biomedica kit $(r=0.20)$. The variability in values generated from Biomedica, R\&D Systems
\end{abstract}

Isabelle Piec

i.piec@uea.ac.uk

1 Bioanalytical Facility, University of East Anglia, Floor 2, Bob Champion Research and Education Building, Norwich Research Park, James Watson Road, Norwich NR4 7UQ, UK

2 Women Ground Close Combat Review, Directorate of Manning (Army), Blenheim Bld, IDL 27, Monxton Road, Andover SP11 8HT, UK

3 Norfolk and Norwich University Hospital, Norwich NR4 7UV, UK and TECOmedical assays raises questions regarding the accuracy and specificity of the assays. Direct comparison of studies using different kits is not possible and great care should be given to measurement of sclerostin, with traceability of reagents. Standardization with appropriate material is required before different sclerostin assays can be introduced in clinical practice.

Keywords Metabolic bone disease - Sclerostin - ELISA . Clinical utility

\section{Introduction}

Sclerostin is a 190-residue secreted protein member of the DAN/Cerberus protein family. Sclerostin was discovered as a product of the SOST gene causing sclerosteosis [1,2], and van Buchem syndrome [3,4], and later confirmed in mice in which the SOST gene had been deleted [5] or overexpressed [6]. Sclerostin is secreted by osteocytes [7] and articular chondrocytes [8] and its absence favours bone formation by lack of inhibition of the canonical Wnt/ $\beta$ catenin signalling [9-11], leading to osteoblast differentiation, proliferation and activity [5, 12].

Circulating sclerostin concentrations are altered in metabolic bone diseases. Sclerostin concentrations are increased in disorders such as hypoparathyroidism [13], type II diabetes $[14,15]$ cancer induced bone disease [16] and Paget's disease [17] and decreased in primary hyperparathyroidism [18-20] and ankylosing spondylitis [21], although recently increased disease activity in ankylosing spondylitis has been associated with higher sclerostin concentrations [22]. Sclerostin may also play a role of importance in patients with chronic kidney disease associated with mineral and bone disorder (for review see [23]). 
High concentrations of circulating sclerostin are suggested to be associated with arterial stiffness, cardiovascular calcification and inflammation, leading to higher morbidity and mortality. However, the results so far are controversial.

Measurement of circulating sclerostin may be helpful in the diagnosis of bone remodelling disorders and assessment of therapeutic effectiveness but concordant results between various assays are necessary for clinical trial comparison. Several assays are available for measurement of sclerostin using human blood. We tested and compared three platebased enzyme-linked immunosorbent assays (ELISA) in serum and ethylene diamine tetra acetic acid (EDTA) plasma samples from healthy young individuals.

\section{Materials and Methods}

\section{Reagents}

ELISA kits were purchased from Biomedica, Vienna, Austria (Sclerostin \#BI-20492 lot Y143), R\&D Systems, Abingdon, United Kingdom (Quantikine ${ }^{\circledR}$ Human SOST immunoassay \#DSST00, lot 318592) and TECOmedical, Sissach, Switzerland (Human Sclerostin EIA, High Sensitivity \#TE1023HS, lot 012455).

\section{Samples}

Anonymised samples from healthy volunteers (aged 18-26 years) were provided by the Ministry of Defence collected in accordance with the Ministry of Defence Research Ethics Committee (MODREC-165). Forty-six serum samples and 27 matching EDTA plasma samples were analysed and sclerostin concentrations were measured following each manufacturer's instructions.

\section{Methods and Statistical Analysis}

For the Biomedica sclerostin ELISA, $150 \mu \mathrm{L}$ assay buffer, $20 \mu \mathrm{L}$ standards, controls and samples and $50 \mu \mathrm{L}$ antisclerostin antibody were loaded per well. Plates were incubated for $24 \mathrm{~h}$ at room temperature $\left(\mathrm{RT}=22{ }^{\circ} \mathrm{C}\right)$ in the dark. The following day, wells were washed five times with $300 \mu \mathrm{L}$ of the wash buffer provided and $200 \mu \mathrm{L}$ conjugate was added and incubated in the dark for $1 \mathrm{~h}$. Wells were washed five times with $300 \mu \mathrm{L}$ of wash buffer,

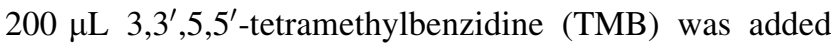
per well, and colour was allowed to develop for $30 \mathrm{~min}$. Stop solution $(50 \mu \mathrm{L})$ was added and absorbance read at $450 \mathrm{~nm}$ with reference at $630 \mathrm{~nm}$.

With the TECOmedical high sensitivity kit, plates were washed for 2 min at RT with $400 \mu \mathrm{L}$ wash buffer (provided) and blot dried. Wells were then loaded with $25 \mu \mathrm{L}$ standards, controls and samples, followed by $50 \mu \mathrm{L}$ matrix and $50 \mu \mathrm{L}$ antibody solutions. Plates were sealed and incubated on a shaker at $500 \mathrm{rpm}$ for $4 \mathrm{~h}$. Wells were washed four times with $400 \mu \mathrm{L}$ wash buffer and then developed in the dark with $100 \mu \mathrm{L}$ TMB solution at RT for $30 \mathrm{~min}$. The reaction was stopped with $100 \mu \mathrm{L}$ of stop solution. Absorbance was measured at $450 \mathrm{~nm}$ with reference at $630 \mathrm{~nm}$.

For the R\&D Systems Sclerostin Quantikine ELISA, $100 \mu \mathrm{L}$ of assay diluent was added to each well, followed by $50 \mu \mathrm{L}$ of standards, controls and samples. Plates were sealed and incubated for $2 \mathrm{~h}$ at RT on a shaker at $500 \mathrm{rpm}$. Plates were then washed four times with $400 \mu \mathrm{L}$ of wash buffer, $200 \mu \mathrm{L}$ of TMB solution added to the wells and colour was allowed to develop for $30 \mathrm{~min}$ in the dark at RT. Finally, $50 \mu \mathrm{L}$ of stop solution was added to each well and absorbance read at $450 \mathrm{~nm}$ with reference at $560 \mathrm{~nm}$.

Results are expressed in $\mathrm{pmol} / \mathrm{L}$ using a multiplying conversion factor of 44 from $\mathrm{ng} / \mathrm{mL}$ to $\mathrm{pmol} / \mathrm{L}$. Values are given as mean $\pm \mathrm{SD}$. Data were analysed using SPSS for windows version 22.0.0.2. Agreement between assays and between the serum and EDTA values were assessed using Passing-Bablock regression, Bland-Altman plots and concordance correlation (CCC) analysis.

\section{Results}

\section{Quality Assessment}

All assays were performed in accordance with the manufacturer's instructions and complied with our standard operating procedures for good laboratory practice. Interassay performance was assessed by calculating the mean, $\mathrm{SD}$ and CV \% of QC material on 6 plates from the same lot over 2 days for Biomedica and TECOmedical and 3 plates over 2 days for R\&D Systems. CVs were $<6 \%$ except for R\&D Systems at $15.3 \mathrm{pmol} / \mathrm{L}$ where a $\mathrm{CV}$ of $14 \%$ was observed (Table 1). We also crossed over the QC material and observed that both R\&D Systems and TECOmedical were close to expected target for each other's QC (except for low level QC TECOmedical), however, they both underestimated Biomedica QC by 25-43\%. QCs from TECOmedical and R\&D Systems were mainly overestimated when measured with the Biomedica kit. In order to estimate the intra-assay imprecision, we calculated the average $\mathrm{CV}$ from duplicates of samples and also run a serum pool four times on two different plates. Results, presented in Table 1, showed that TECOmedical performed best with $\mathrm{CV}<4.5 \%$ and only 1 sample with a $\mathrm{CV}>10 \%$. However, both Biomedica and R\&D Systems showed high CVs on serum and EDTA with CVs up to $35 \%$ for R\&D Systems and $69 \%$ for Biomedica). Similar 
Table 1 Intra- and inter-assay data for the measurement of sclerostin using Biomedica, TECOmedical and R\&D Systems kits

\begin{tabular}{|c|c|c|c|c|c|c|c|}
\hline \multirow[t]{2}{*}{ Intra-assay } & \multicolumn{4}{|c|}{ Mean of $\% \mathrm{CV} \pm \mathrm{SEM}$ (maximum $\% \mathrm{CV}$ ) } & \multirow{2}{*}{\multicolumn{3}{|c|}{$\begin{array}{l}\text { Serum pool } \\
\% \mathrm{CV} \text { plate } 1 \text { and } 2\end{array}$}} \\
\hline & \multicolumn{2}{|c|}{ Serum $(n=46)$} & \multicolumn{2}{|c|}{ EDTA $(n=27)$} & & & \\
\hline Biomedica & \multicolumn{2}{|c|}{$8.2 \pm 1.6^{*}(68.8 \%)$} & \multicolumn{2}{|c|}{$7.6 \pm 1.2 *(20.3 \%)$} & \multicolumn{3}{|c|}{33 and $9.9 \%$} \\
\hline TECOmedical & \multicolumn{2}{|c|}{$2.7 \pm 0.4(11.3 \%)$} & \multicolumn{2}{|c|}{$2.7 \pm 0.5(8.9 \%)$} & \multicolumn{3}{|c|}{4.5 and $2.8 \%$} \\
\hline R\&D Systems & \multicolumn{2}{|c|}{$5.0 \pm 1.1(35 \%)$} & \multicolumn{2}{|c|}{$7.3 \pm 1.0^{*}(16.7 \%)$} & \multicolumn{3}{|c|}{9.2 and $3.9 \%$} \\
\hline Inter-assay & Biomedica & \multicolumn{2}{|l|}{ TECOmedical } & \multicolumn{3}{|c|}{ R\&D Systems } & \\
\hline Mean (pmol/L) & 87.7 & 8.2 & 92.1 & 9.2 & 15.3 & & 37.7 \\
\hline SD & 2.8 & 0.4 & 3.6 & 0.2 & 2.2 & & 2.2 \\
\hline $\mathrm{CV}$ & 3.2 & 4.4 & 3.9 & 2.4 & 14.3 & & 5.8 \\
\hline \multicolumn{8}{|c|}{ QC cross-over in pmol/L (deviation to target \%) } \\
\hline Biomedica QC & & $23.6(+187)$ & $144.6(+57)$ & $18.3(+98)$ & 23.9 & $(+56)$ & $44.3(+17)$ \\
\hline TECOmedical QC & $50.2(-43)$ & & & $9.2(-0.3)$ & 14.5 & $(-5.3)$ & $34.3(-9.1)$ \\
\hline R\&D systems QC & $65.6(-25)$ & $6.2(-25)$ & $88.3(-4)$ & & & & \\
\hline
\end{tabular}

Intra-assay was estimated using the mean $\pm \mathrm{SEM}$ of the $\mathrm{CV}$ s from samples run in duplicates and a serum pool run six times on two different plates. Inter-assay was estimated by repeated measure of QC material on different plates

Statistical significance, $* p<0.05$ as compared to TECOmedical results were obtained with the serum pool run in quadruplicate as Biomedica showed a CV of $33 \%$.

We assessed the linearity (Table 2 ) of the assays by diluting serum and EDTA samples by two-, four- and eight-fold using the sample diluent provided in the kits. Upon 1:2 and 1:4 dilutions, sclerostin concentrations were $111 \& 89 \%$ and $97 \& 103 \%$ of the expected concentration for R\&D Systems and TECOmedical, respectively. Upon 1:8 dilution TECOmedical sclerostin concentration was $107 \%$ of the expected concentration for TECOmedical; however, as the neat concentration of the samples were already very low, 1:8 dilution lead to irrelevant values when measured using the R\&D Systems assay. When using the Biomedica assay, samples were consistently over-recovered upon dilution (146, 147 and $139 \%$ after 1:2;1:4 and $1: 8$ dilution).

Spiked recovery (\%) was determined by adding a known quantity of purified sclerostin (from QC material with each assay) to samples containing a range of endogenous sclerostin. Results (Table 2) were very similar between the kits and close to $100 \%$ with Biomedica: $100.6 \pm 4.1 \%$; TECOmedical: $\quad 97.4 \pm 4.7 \%$ and R\&D Systems: $97.6 \pm 3.0 \%$.

\section{Sclerostin Measurements}

Samples were analysed at the same time using all three kits so differences could not be attributed to differences in sample handling such as freeze/thaw cycles. For each provider, assays were performed using the same lot number and the samples had only been through one freeze-thaw cycle. Recommended maximum freeze-thaw cycles were 4 for Biomedica and 3 for TECOmedical (no data available for R\&D Systems). Table 3 shows mean \pm SEM of sclerostin as well as minimum and maximum values obtained with the different assays and depending on collection tube.

We obtained significantly different values for sclerostin concentrations measured in EDTA plasma samples by each
Table 2 Linearity and recovery data for the measurement of serum sclerostin using Biomedica, TECOmedical and R\&D Systems kits

\begin{tabular}{lcccc}
\hline & \multicolumn{2}{l}{ Linearity $(\% \pm$ SEM $)$} & Recovery $(\% \pm$ SEM $)$ \\
\cline { 2 - 4 } & $1: 2$ & $1: 4$ & $1: 8$ & \\
\hline Biomedica & $146.7 \pm 18.3^{*}$ & $147.4 \pm 16.9^{*}$ & $139.1 \pm 7.0^{*}$ & $100.6 \pm 4.1$ \\
TECOmedical & $97.2 \pm 3.5$ & $103.2 \pm 3.8$ & $107.1 \pm 7.1$ & $97.4 \pm 4.7$ \\
R\&D Systems & $110.6 \pm 18.6$ & $88.5 \pm 14.2$ & $685.4 \pm 79.1^{* * *}$ & $97.6 \pm 3.0$ \\
\hline
\end{tabular}

Linearity was assessed by diluting samples up to eight-fold. Recovery was assessed by spiking samples with known concentration of QC material

Statistical significance, $* p<0.05$ Biomedica versus TECOmedical and R\&D Systems, *** $p<0.001$ R\&D Systems versus TECOmedical and Biomedica 
Table 3 Sclerostin concentrations measured with $\mathrm{R} \& \mathrm{D}$ Systems, TECOmedical and Biomedica kits in pmol/L and presented as mean \pm SEM along with the minimum and maximum values (and the SD)

\begin{tabular}{|c|c|c|c|c|}
\hline & \multicolumn{2}{|c|}{ Serum $(\mathrm{SOST}) \mathrm{pmol} / \mathrm{L} n=46$} & \multicolumn{2}{|c|}{ EDTA $(\mathrm{SOST}) \mathrm{pmol} / \mathrm{L} n=27$} \\
\hline & Mean \pm SEM & Min-max (SD) & Mean \pm SEM & Min-max (SD) \\
\hline Biomedica & $35.5 \pm 1.1^{* *,+\dagger}$ & $22.3-58.9(7.3)$ & $39.4 \pm 2.0$ & $22.9-71.1(10.3)$ \\
\hline TECOmedical & $21.8 \pm 0.7$ & $11.4-32.6(4.8)$ & $27.2 \pm 1.3$ & $13.8-49.1(6.9)$ \\
\hline R\&D Systems & $7.6 \pm 0.4 * *$ & $2.7-13.2(2.4)$ & $30.9 \pm 1.5$ & $15.4-53.0(7.8)$ \\
\hline
\end{tabular}

** $p<0.001$ versus TECOmedical; ${ }^{\dagger \dagger} p<0.001$ versus R\&D Systems kit. The Biomedica assay detected the significantly highest results up to a concentration of $32 \mathrm{pmol} / \mathrm{L}$ and on average, $29.5 \%(p<0.001)$ and $19.8 \%(p<0.001)$ higher than TECOmedical and R\&D Systems assays, respectively. EDTA sclerostin measured by TECOmedical and R\&D Systems were not significantly different. Passing-Bablock regression and concordance correlation analyses (Fig. 1 right panel; Table 4) showed a linear relationship with systematic and proportional differences between the assays when using the EDTA samples. Although R\&D Systems gave values $13.8 \%$ lower than TECOmedical, we observed a good correlation between the two assays when using EDTA samples with Pearson coefficient of 0.96 but a poor agreement between the two methods with CCC of 0.85 (95\% CI 0.738-0.912) and a bias correction of 0.88 . Bland-Altman plot showed that the bias was small and similar across the range of concentrations. Biomedica results did not correlate with the other kits and concordance correlations were very poor (CCC of 0.46 and 0.33 versus R\&D Systems and TECOmedical, respectively, with $95 \%$ CI 0.223-0.627 and 0.153-0.486 and Pearson coefficient of 0.68 and 0.71 ; correction bias were 0.67 and 0.47 ). BlandAltman plots (Fig. 2) also showed the bias increased with higher the concentration of sclerostin.

Larger discrepancies were observed with serum samples. Biomedica gave an average of 37.1 and $77.9 \%$ higher concentrations versus TECOmedical and R\&D systems, respectively (Fig. 1 left panel; Table 3); discrepancies being up to $50 \mathrm{pmol} / \mathrm{L}(p<0.001)$. Biomedica results showed very poor correlation with the two other kits with extremely poor concordance between the results $(\mathrm{CCC}<0.08$ and Pearson correlation coefficient $<0.29)$. TECOmedical and R\&D Systems correlated with $r=0.78$, however, R\&D systems gave lower results $(65 \%$ on average) and extremely poor value agreement (CCC of $0.0895 \%$ CI $0.041-0.113$ ) and Cusum test for linearity indicates significant deviation from linearity $(p<0.05)$. Bland-Altman plots (Fig. 3) showed a negative bias that increased proportionally as the concentrations increases for both R\&D Systems versus TECOmedical and R\&D Systems and Biomedica. When comparing TECOmedical to Biomedica, Bland-Altman plot showed that the bias was mainly present for high concentrations of sclerostin.

\section{Matrix Effect}

Serum sclerostin concentrations (Table 3) were significantly lower than EDTA for TECOmedical (serum: $21.8 \pm 4.8 \mathrm{pmol} / \mathrm{L}$ versus $\quad$ EDTA $27.2 \pm 6.9 \mathrm{pmol} / \mathrm{L}$ $p<0.03$ ) and for R\&D Systems (serum: $7.6 \pm 2.4 \mathrm{pmol} / \mathrm{L}$ versus EDTA $19.0 \pm 4.7 \mathrm{pmol} / \mathrm{L} p<0.01$ ) which also displayed a very low CCC of 0.04 although the correlation coefficient was 0.85 in the Passing-Bablock analysis (Table 4; Fig. 4). Passing-Bablock analysis also showed good correlation but poor correspondence of serum and EDTA results for TECOmedical (CCC of $0.7895 \% \mathrm{CI}$ 0.63-0.87 and Pearson correlation coefficient of 0.9). When using the Biomedica kit, serum and EDTA showed poor correlation $(0.20)$ with differences between -26.6 and $113.9 \%$ and a no agreement with a very low CCC of 0.2 . Bland-Altman plots showed that there was virtually no bias between EDTA and Serum measurements when using the TECOmedical kit, there was a negative bias that proportionally increased with increasing concentrations of sclerostin when using R\&D Systems kits and the bias was present mainly at the highest concentrations for Biomedica, however, the CI was larger than the two other kits.

\section{Discussion}

We analysed serum and matching EDTA plasma samples from healthy young men and women aged 18-26 years using commercially available kits from Biomedica, TECOmedical and R\&D Systems. In general the kits performed according to the manufacturer's inserts for interassay characteristics (performed on QC material) as well as spiked recovery. The Biomedica assay showed a poor linearity on dilution of samples with diluted recovery of $145 \%$. It has been suggested that heparin as an anticoagulant could interfere with the binding of sclerostin to proteins such as LRP5/6 and the antibodies used in some assays [24]; we therefore used only EDTA plasma and serum samples in this evaluation. Overall, we found that measurements on EDTA samples were more comparable between assays (lower differences in values and better correlations between kits) than on serum samples. This 

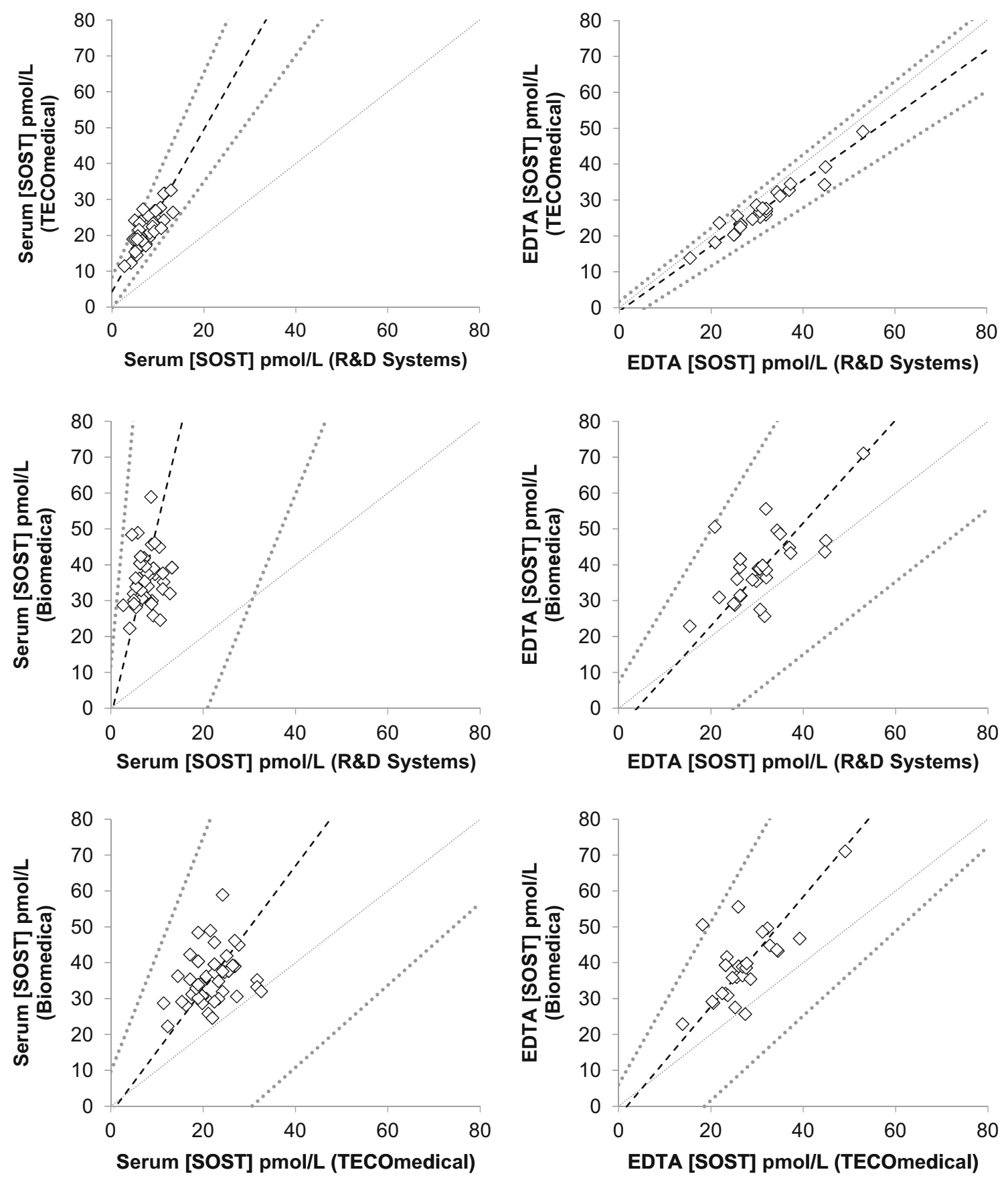

Fig. 1 Passing-Bablock regression analysis for serum (left panel) and EDTA (right panel) samples comparing the three different ELISA kits for circulating sclerostin measurements. Dash line represents the

fitted regression line; dark grey dotted lines represent upper and lower $95 \%$ confidence and light grey dotted line represent the identity line

difference could be due to the separation technique. During coagulation in serum samples, clot formation removes proteins such as fibrinogen from the blood sample potentially trapping part of the sclerostin. During the clotting process, platelets get activated inducing the release of various metabolites, which can alter analyte levels relative to plasma [25-27].

The Biomedica assay gave systematically the highest results on samples or QC material from the two other kits. $\mathrm{R} \& \mathrm{D}$ Systems, on the other hand, produced very low values when using serum samples. Cross-over measurement of QC material showed that both R\&D Systems and TECOmedical were relatively accurate and close to the expected target for each other's QC, however, both 
Table 4 Passing-Bablock and Lin's concordance correlation analyses comparing sclerostin ELISA kits on EDTA and serum samples

\begin{tabular}{|c|c|c|c|c|c|c|c|c|c|}
\hline \multirow[t]{2}{*}{ EDTA } & \multicolumn{5}{|c|}{ Passing-Bablock regression analysis } & \multicolumn{4}{|c|}{ Concordance correlation analysis } \\
\hline & Intercept & $95 \% \mathrm{CI}$ & Slope & $95 \% \mathrm{CI}$ & Cusum test & $\mathrm{CCC}$ & $95 \% \mathrm{CI}$ & $r$ & $\mathrm{Cb}$ \\
\hline R\&D Systems versus TECOmedical & -1.0 & $-4.68-1.73$ & 0.9 & $0.81-1.0$ & No & 0.846 & $0.738-0.912$ & 0.964 & 0.878 \\
\hline Biomedica versus R\&D Systems & -5.7 & $-25.5-7.3$ & 1.4 & $1.0-2.1$ & No & 0.455 & $0.223-0.627$ & 0.681 & 0.667 \\
\hline Biomedica versus TECOmedical & -2.8 & $-22.0-6.0$ & 1.5 & $1.2-2.7$ & No & 0.330 & $0.153-0.486$ & 0.710 & 0.464 \\
\hline \multirow[t]{2}{*}{ SERUM } & \multicolumn{5}{|c|}{ Passing-Bablock regression analysis } & \multicolumn{4}{|c|}{ Concordance correlation analysis } \\
\hline & Intercept & $95 \% \mathrm{CI}$ & Slope & $95 \% \mathrm{CI}$ & Cusum test & $\mathrm{CCC}$ & $95 \% \mathrm{CI}$ & $r$ & $\mathrm{Cb}$ \\
\hline R\&D Systems versus TECOmedical & 4.3 & -0.3 to 8.4 & 2.6 & $1.7-2.8$ & Yes & 0.077 & 0.041 to 0.113 & 0.780 & 0.099 \\
\hline Biomedica versus R\&D Systems & -2.3 & -65.4 to 11.7 & 5.3 & $3.2-14.2$ & No & 0.007 & -0.006 to 0.02 & 0.175 & 0.041 \\
\hline Biomedica versus TECOmedical & -1.9 & -35.0 to 9.7 & 1.7 & $1.1-3.3$ & No & 0.076 & -0.008 to 0.158 & 0.288 & 0.263 \\
\hline
\end{tabular}

$C I$ confidence interval; $C C C$ concordance correlation coefficient; $r$ : Pearson correlation coefficient; $C b$ bias correction. EDTA results showed good correlation between the kits $(r>0.68)$. However, results obtained with the Biomedica kit using serum samples did not correlate with either TECOmedical $(r=0.29)$ or R\&D Systems $(r=0.18)$ and showed poor concordance $(\mathrm{CCC}<0.08)$

Fig. 2 Bland-Altman plots for sclerostin concentrations in EDTA plasma comparing the three different ELISA kits. R\&D systems showed little bias when compared to TECOmedical while both R\&D Systems and TECOmedical assays showed a negative bias (and wide $\mathrm{CI}$ ) compared to

Biomedica; bias present mainly at the highest concentrations of sclerostin
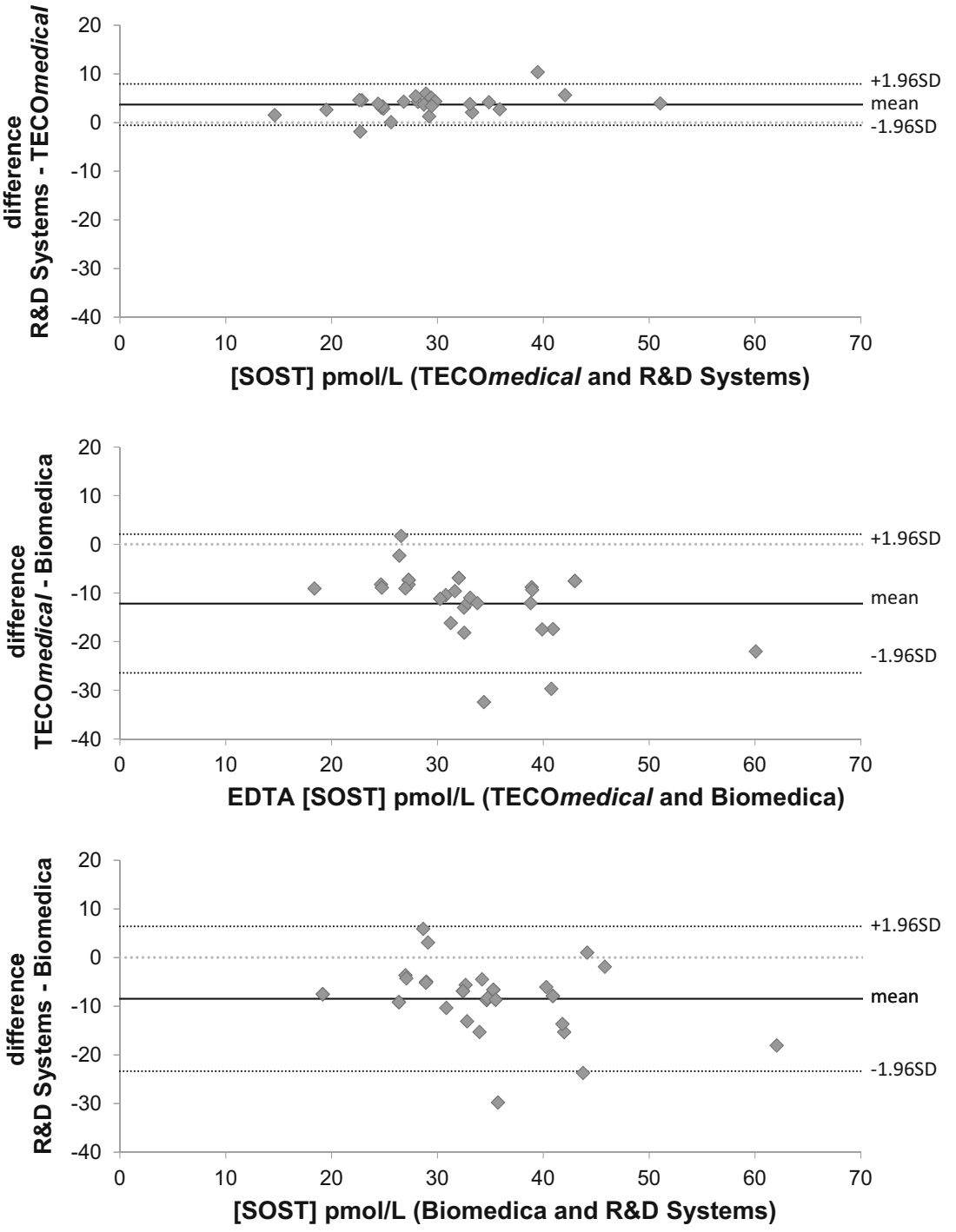
Fig. 3 Bland-Altman plots for sclerostin concentrations in serum comparing the three systems showed a negative bias when compared to

TECOmedical as well as Biomedica that proportionally increased with increasing concentrations of sclerostin. TECOmedical showed a negative bias compared to Biomedica which affected mainly the highest concentrations of sclerostin different ELISA kits. R\&D
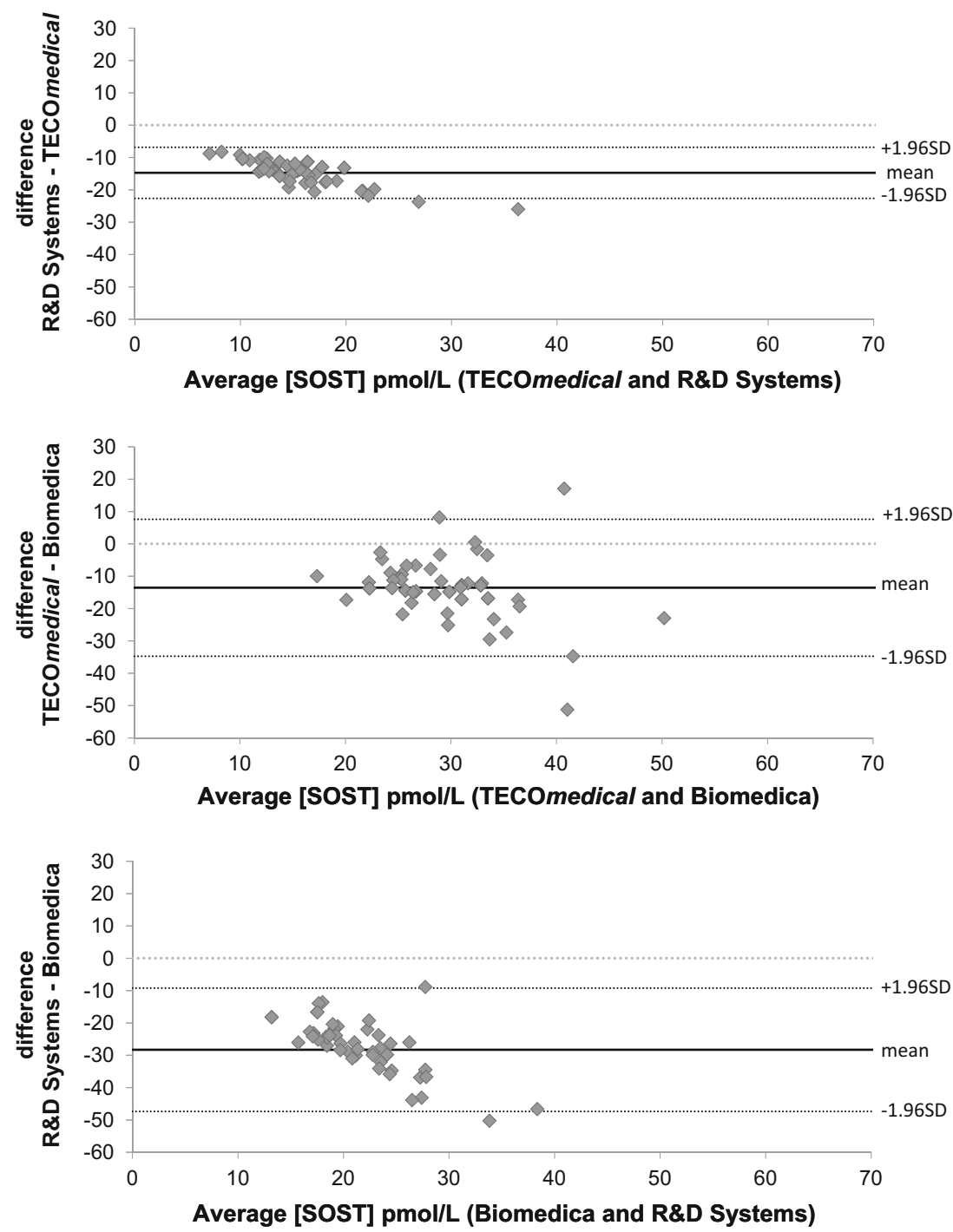

underestimated Biomedica QC. The discrepancies, we observed between the sclerostin concentrations (as for the reference ranges) suggest that the three assays are measuring different forms of the protein and/or the specificity of the antibody used is different. As previously reported, Biomedica and TECOmedical assays can be affected by interfering substances [28] which may partly account for the poor linearity and the high CVs observed when using the Biomedica kit.

We found poor correlation (0.3) and no agreement of values between TECOmedical and Biomedica assays using serum samples. These results are conflicting with a similar study from Costa et al. [28] who showed a correlation of 0.9 with systematic and proportional differences between the two methods. This difference could be attributed to the fact that Costa et al. used the Sclerostin TECO $^{\circledR}$ kit which is the previous sclerostin assay developed by TECOmedical while we used the new version of the assay marked as
Human Sclerostin EIA High Sensitivity. This is a different kit, with different antibodies and a different manufacturer's protocol, which could very well account for the differences in the raw sclerostin values obtained. Also we used samples from pre-menopausal (18-26 year-old) healthy participants while previous studies used samples from a mix of younger and older patients and/or suffering from bone-affecting disorders. Concentrations of sclerostin measured using the Biomedica ELISA, however, were very similar being $>30 \mathrm{pmol} / \mathrm{L}$ on average in both EDTA plasma and serum; differences quoted are potentially attributable to variation between kit lot numbers. The concentrations of sclerostin we measured using the TECOmedical assay are $\sim 30 \%$ lower than previously published data in serum and EDTA [24, 28] (but [30] in serum).

This is the first study comparing different kits that included the ELISA assay from R\&D Systems. The results indicate comparable raw results and good correlation with 
Fig. 4 Bland-Altman plots comparing sclerostin concentration in serum versus EDTA plasma using the three different ELISA kits.

TECOmedical showed very little bias between serum and EDTA samples. There was a systematic and proportional negative bias with the $R \& D$ Systems assay (from -11 to $-38 \mathrm{pmol} / \mathrm{L}$ ). The bias was present mainly for the high concentrations of sclerostin using the Biomedica assays
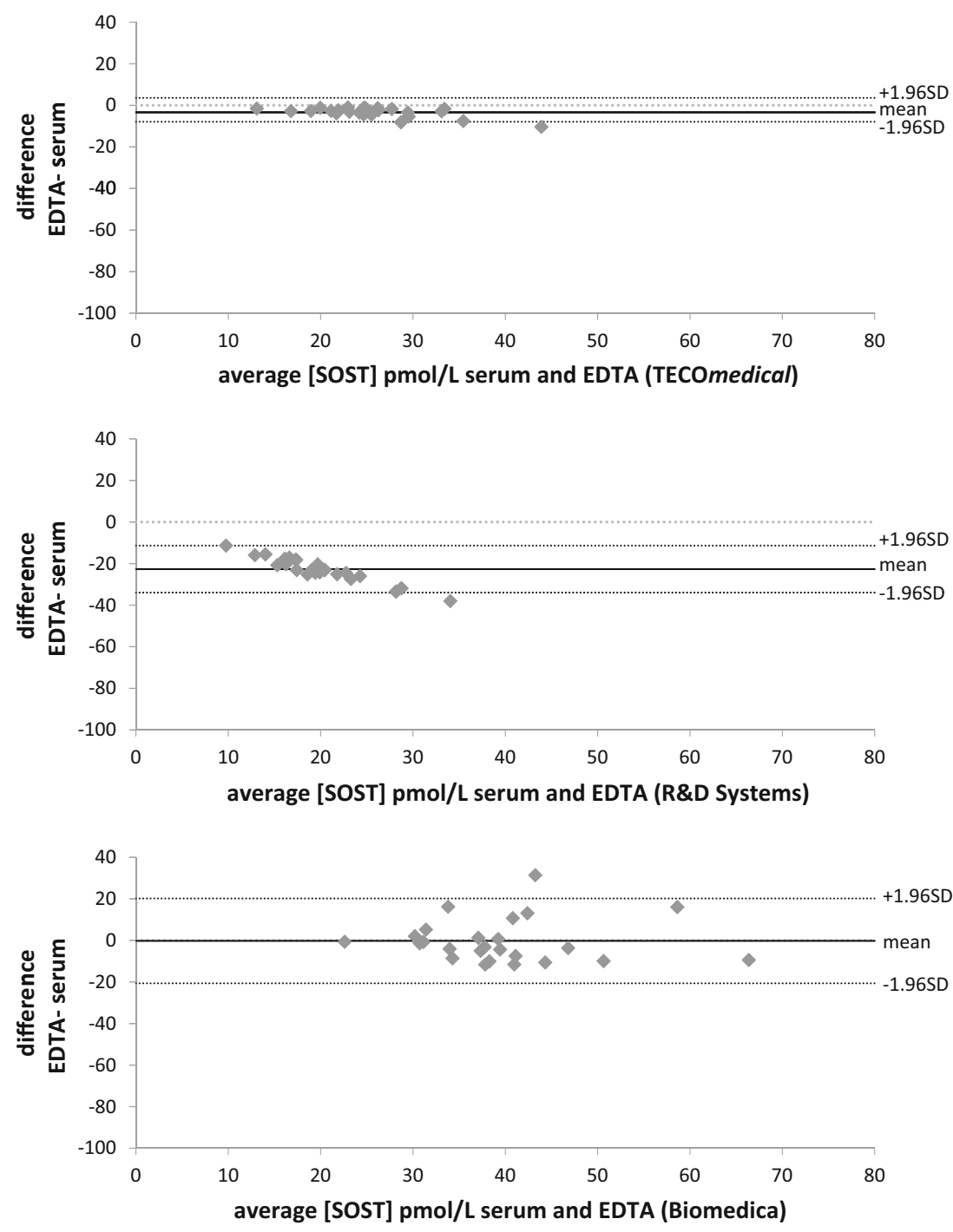

TECOmedical when using EDTA plasma samples. Serum values are lower with the results reflecting those obtained with the Meso Scale Discovery platform [30] of 0.8-3 pmol/L, suggesting that the R\&D System kit could be detecting only intact sclerostin. More research is required to answer this question, but variation between lot numbers may be the cause of some of the differences observed.

Given the differences between assays, the results and reference ranges will be assay-specific and specific to sample type. However, comparing mean sclerostin concentrations obtained with mean values quoted by manufacturers for healthy donors, values for TECOmedical were within the expected reference range. Only 2 and $4 \%$ of samples, respectively, for serum and EDTA were above the reference range for R\&D Systems. However, $20 \%$ of serum samples were above the quoted reference range when using the Biomedica assay. No reference range was given for EDTA plasma samples by this manufacturer, however, in their matrix comparison 8 EDTA samples were analysed giving a mean at $18.2 \mathrm{pmol} / \mathrm{L}$ leading us to believe a similar gap would be expected between our values and the reference range. This result is in accordance with Moysés et al. [29] who found an extra $25 \%$ of hemodialysed patients were above the reference range when using Biomedica versus TECOmedical. These differences could have important consequences for patients that are falsely classified as over the range or inversely as presenting normal levels of sclerostin as we cannot to date determine what each assay is actually measuring.

Following its discovery in 2001, interest in sclerostin has expanded in recent years with over 100 publications in 2014. As the knowledge about structure and function of sclerostin is progressively unveiled, sclerostin is being suggested as a "predictor" and "biomarker" for diseases such as chronic kidney disease (CKD) [31], aortic valve 
calcification [32], osteoporotic fracture [33] or spinal cord injury induced osteoporosis [34]. In CDK in particular, evidence points to a central role of sclerostin in the kidneybone-vascular axis. As the disease progresses, patients with chronic kidney disease also suffer from vascular calcification and osteodystrophy (CDK-MBD) leading to higher morbidity and mortality. Although the exact pathway is yet to be elucidated and results can be inconsistent, two hypotheses have emerged. Bone-originating sclerostin may have an indirect counter-regulatory action on the vascular calcification via the regulation of the production of other hormones and/or sclerostin may be produced locally when the environment becomes calcifying (for reviews see $[23,35,36])$. Circulating sclerostin concentrations have been reported to vary by sex, age, season and severity of diseases and treatment. The variability in measurement adds to the complexity in drawing conclusions on the role of sclerostin.

As focus grows on sclerostin, authors are rightly being cautious, as we are in this publication, highlighting the need for a consensus and standardization, of the assays to measure sclerostin before sclerostin assays can be used as routine diagnostic tools for metabolic bone diseases. It may be necessary to consider the use of external reference materials for quality control and quality assurance of these assays.

Acknowledgments We gratefully thank the army volunteers for providing samples that were used in this study.

\section{Compliance with ethical standards}

Conflict of interest Isabelle Piec, Christopher Washbourne, Jonathan Tang, Emily Fisher, Julie Greeves, Sarah Jackson and William D. Fraser have no conflict of interest to disclose.

Human and Animal Rights and Informed Consent This study was ethically approved by the Ministry of Defence and performed in accordance with the Ministry of Defence Research Ethics Committee (MODREC-165) and the ethical principles of the University of East Anglia for research and development.

Open Access This article is distributed under the terms of the Creative Commons Attribution 4.0 International License (http://crea tivecommons.org/licenses/by/4.0/), which permits unrestricted use, distribution, and reproduction in any medium, provided you give appropriate credit to the original author(s) and the source, provide a link to the Creative Commons license, and indicate if changes were made.

\section{References}

1. Brunkow ME, Gardner JC, Van Ness J et al (2001) Bone dysplasia sclerosteosis results from loss of the SOST gene product, a novel cystine knot-containing protein. Am J Hum Genet 68:577-589. doi:10.1086/318811
2. Balemans W, Ebeling M, Patel N et al (2001) Increased bone density in sclerosteosis is due to the deficiency of a novel secreted protein (SOST). Hum Mol Genet 10:537-543. doi:10.1093/Hmg/ 10.5.537

3. Balemans W, Patel N, Ebeling M et al (2002) Identification of a $52 \mathrm{~kb}$ deletion downstream of the SOST gene in patients with van Buchem disease. J Med Genet 39:91-97. doi:10.1136/jmg.39.2. 91

4. Staehling-Hampton K, Proll S, Paeper BW et al (2002) A 52-kb deletion in the SOST-MEOX1 intergenic region on 17q12-q21 is associated with van Buchem disease in the Dutch population. Am J Med Genet 110:144-152. doi:10.1002/ajmg.10401

5. Li X, Ominsky MS, Niu Q et al (2008) Targeted deletion of the sclerostin gene in mice results in increased bone formation and bone strength. J Bone Miner Res 23:860-869. doi:10.1359/jbmr. 080216

6. Kramer I, Loots GG, Studer A et al (2010) Parathyroid hormone (PTH)-induced bone gain is blunted in SOST overexpressing and deficient mice. J Bone Miner Res 25:178-189. doi:10.1359/jbmr. 090730

7. Van Bezooijen RL, Roelen BAJ, Visser A et al (2004) Sclerostin is an osteocyte-expressed negative regulator of bone formation, but not a classical BMP antagonist. J Exp Med 199:805-814. doi:10.1084/jem.20031454

8. Roudier M, Li X, Niu QT et al (2013) Sclerostin is expressed in articular cartilage but loss or inhibition does not affect cartilage remodeling during aging or following mechanical injury. Arthritis Rheumatol 65:721-731. doi:10.1002/art.37802

9. Winkler DG, Kung Sutherland MS, Ojala E et al (2005) Sclerostin inhibition of Wnt-3a-induced C3H10T1/2 cell differentiation is indirect and mediated by bone morphogenetic proteins. J Biol Chem 280:2498-2502. doi:10.1074/jbc.M400524200

10. Li X, Zhang Y, Kang H et al (2005) Sclerostin binds to LRP5/6 and antagonizes canonical Wnt signaling. J Biol Chem 280: 19883-19887. doi:10.1074/jbc.M413274200

11. Semënov M, Tamai K, He X (2005) SOST is a ligand for LRP5/ LRP6 and a Wnt signaling inhibitor. J Biol Chem 280:26770 26775. doi:10.1074/jbc.M504308200

12. Baron R, Rawadi G (2007) Minireview: targeting the $W n t / \beta$ catenin pathway to regulate bone formation in the adult skeleton. Endocrinology 148:2635-2643. doi:10.1210/en.2007-0270

13. Costa AG, Cremers S, Rubin MR et al (2011) Circulating sclerostin in disorders of parathyroid gland function. J Clin Endocrinol Metab 96:3804-3810. doi:10.1210/jc.2011-0566

14. García-Martín A, Rozas-Moreno P, Reyes-García R et al (2012) Circulating levels of sclerostin are increased in patients with type 2 diabetes mellitus. J Clin Endocrinol Metab 97:234-241. doi:10. 1210/jc.2011-2186

15. Gennari L, Merlotti D, Valenti R et al (2012) Circulating sclerostin levels and bone turnover in type 1 and type 2 diabetes. J Clin Endocrinol Metab 97:1737-1744. doi:10.1210/jc.20112958

16. Gkotzamanidou M, Dimopoulos MA, Kastritis E et al (2012) Sclerostin: a possible target for the management of cancer-induced bone disease. Expert Opin Ther Targets 16:761-769. doi: $10.1517 / 14728222.2012 .697154$

17. Yavropoulou MP, van Lierop AH, Hamdy NAT et al (2012) Serum sclerostin levels in Paget's disease and prostate cancer with bone metastases with a wide range of bone turnover. Bone 51:153-157. doi:10.1016/j.bone.2012.04.016

18. Van Lierop AH, Witteveen JE, Hamdy NAT, Papapoulos SE (2010) Patients with primary hyperparathyroidism have lower circulating sclerostin levels than euparathyroid controls. Eur J Endocrinol 163:833-837. doi:10.1530/EJE-10-0699

19. Ardawi MS, Al-Sibiany AM, Bakhsh TM et al (2011) Decreased serum sclerostin levels in patients with primary 
hyperparathyroidism: a cross-sectional and a longitudinal study. Osteoporos Int. doi:10.1007/s00198-011-1806-8

20. Viapiana O, Fracassi E, Troplini S et al (2013) Sclerostin and DKK1 in primary hyperparathyroidism. Calcif Tissue Int 92:324-329. doi:10.1007/s00223-012-9665-7

21. Appel H, Ruiz-Heiland G, Listing J et al (2009) Altered skeletal expression of sclerostin and its link to radiographic progression in ankylosing spondylitis. Arthritis Rheumatol 60:3257-3262. doi:10.1002/art.24888

22. Korkosz M, Gąsowski J, Leszczyński P et al (2013) High disease activity in ankylosing spondylitis is associated with increased serum sclerostin level and decreased wingless protein-3a signaling but is not linked with greater structural damage. BMC Musculoskelet Disord 14:99. doi:10.1186/1471-2474-14-99

23. Evenepoel P, D'Haese P, Brandenburg V (2015) Sclerostin and DKK1: new players in renal bone and vascular disease. Kidney Int 88:235-240. doi:10.1038/ki.2015.156

24. McNulty M, Singh RJ, Li X et al (2011) Determination of serum and plasma sclerostin concentrations by enzyme-linked immunoassays. J Clin Endocrinol Metab. doi:10.1210/jc.2011-0254

25. O'Neal WK, Anderson W, Basta PV et al (2014) Comparison of serum, EDTA plasma and P100 plasma for luminex-based biomarker multiplex assays in patients with chronic obstructive pulmonary disease in the SPIROMICS study. J Transl Med 12:9. doi:10.1186/1479-5876-12-9

26. Yu Z, Kastenmüller G, He Y et al (2011) Differences between human plasma and serum metabolite profiles. PLoS One. doi:10. 1371/journal.pone.0021230

27. Banks RE, Stanley AJ, Cairns DA et al (2005) Influences of blood sample processing on low-molecular-weight proteome identified by surface-enhanced laser desorption/ionization mass spectrometry. Clin Chem 51:1637-1649. doi:10.1373/clinchem.2005.051417

28. Costa AG, Cremers S, Dworakowski E et al (2014) Comparison of two commercially available ELISAs for circulating sclerostin. Osteoporos Int 25:1547-1554. doi:10.1007/s00198-014-2635-3
29. Moysés RM, Jamal SA, Graciolli FG et al (2015) Can we compare serum sclerostin results obtained with different assays in hemodialysis patients? Int Urol Nephrol 47:847-850. doi:10. 1007/s11255-015-0971-7

30. Durosier C, Van Lierop A, Ferrari S et al (2013) Association of circulating sclerostin with bone mineral mass, microstructure, and turnover biochemical markers in healthy elderly men and women. J Clin Endocrinol Metab 98:3873-3883. doi:10.1210/jc.20132113

31. Holmes D (2014) Biomarkers: sclerostin levels linked to CKD outcomes. Nat Rev Endocrinol 10:577. doi:10.1038/nrendo.2014. 145

32. Koos R, Brandenburg V, Mahnken AH et al (2013) Sclerostin as a potential novel biomarker for aortic valve calcification: an in vivo and ex vivo study. J Heart Valve Dis 22:317-325

33. Ardawi M-SM, Rouzi AA, Al-Sibiani SA et al (2012) High serum sclerostin predicts the occurrence of osteoporotic fractures in postmenopausal women: the Center of Excellence for Osteoporosis Research Study. J Bone Miner Res 27:2592-2602. doi:10. 1002/jbmr. 1718

34. Morse LR, Sudhakar S, Lazzari AA et al (2013) Sclerostin: a candidate biomarker of SCI-induced osteoporosis. Osteoporos Int 24:961-968. doi:10.1007/s00198-012-2072-0

35. Pelletier S, Confavreux CB, Haesebaert J et al (2015) Serum sclerostin: the missing link in the bone-vessel cross-talk in hemodialysis patients? Osteoporos Int 26:2165-2174. doi:10. 1007/s00198-015-3127-9

36. Brandenburg VM, D'Haese P, Deck A et al (2015) From skeletal to cardiovascular disease in 12 steps-the evolution of sclerostin as a major player in CKD-MBD. Pediatr Nephrol. doi:10.1007/ s00467-015-3069-7 